\title{
Conversion from Cyclosporin A to Tacrolimus as a Non-Surgical Alternative to Reduce Gingival Enlargement: A Preliminary Case Series
}

\author{
Gonzalo Hernández, * Lorenzo Arriba, * María Cruz Frías, * José Carlos de la Macorra, ${ }^{\dagger}$ \\ Juan Carlos de Vicente, ${ }^{\ddagger}$ Carlos Jiménez,,${ }^{\S}$ Amado de Andrés, ${ }^{i}$ and Enrique Moreno $\$$
}

Background: Gingival enlargement (GE) is a frequent side effect that occurs in organ transplant recipients (OTR) after the administration of cyclosporin A (CsA). The availability of new drugs used to suppress graft rejection in OTR offers an opportunity to manage GE non-surgically. This preliminary case series aimed to analyze the effect of CsA withdrawal and its substitution by another immunosuppressant in OTR with severe GE.

Methods: Four organ transplant recipients who had received a liver or renal allograft were recruited for this study. All OTR had developed clinically severe CSA-induced GE. GE scores were assessed for each patient at baseline and at weeks 2, 4, 8, 12, 16, and 54 following conversion to tacrolimus. Scaling and root planing were initially performed and repeated monthly during the first 6 months. Careful polishing of the teeth was carried out once every 2 weeks until month 6 and then monthly until month 12. Hygiene instructions and reinforcement to optimize oral hygiene were maintained throughout the study.

Results: The four patients showed a rapid decrease in their gingival symptoms and in the size of the gingivae. This change was clinically evident 8 weeks after conversion to tacrolimus. One year later, all the patients experienced GE regression, although some anatomic irregularities persisted in the interdental papillae of one of the patients. No adverse effects from tacrolimus were observed during the study except in one patient who presented headaches.

Conclusion: It seems that CsA withdrawal and its conversion to tacrolimus in organ transplant recipients who develop severe gingival enlargement, together with an extensive plaque control program, provide an effective means to control/eliminate gingival hyper-

\footnotetext{
* Department of Oral Medicine and Buccofacial Surgery, School of Dentistry, Complutense University, Madrid, Spain

† Department of Restorative Dentistry, Complutense University.

₹ Department of Maxillofacial Surgery, University Hospital and School of Medicine, Oviedo, Spain

$\S$ Department of General Digestive Surgery and Abdominal Transplant Organs, Hospital 12 de Octubre, Complutense University.

i Department of Nephrology, Hospital 12 de Octubre, Complutense University.
}

plasia, with minimal risk of graft dysfunction. J Periodontol 2003; 74:1816-1823.

\section{KEY WORDS}

Cyclosporin A/adverse effects; follow-up studies; gingival hyperplasia/etiology; gingival hyperplasia/ therapy; organ transplantation/complications; tacrolimus/therapeutic use.

Gingival enlargement (GE) may occur as a result of the administration of certain drugs, especially phenytoin, ${ }^{1}$ calcium channel blockers, ${ }^{2}$ and cyclosporin A $(\mathrm{CsA}){ }^{3}$ The incidence of drug-induced $\mathrm{GE}$ varies according to several factors; however, the exact mechanism for the development of GE is still unknown. ${ }^{4,5}$ Gingival size in these patients may be affected to different degrees, from slight overgrowth to severe enlargement, which may interfere with oral function and create esthetic problems.

Since its introduction into clinical practice by Calne in $1978,{ }^{6} \mathrm{CsA}$ has been used during the last 2 decades as the main immunosuppressant to prevent graft rejection in solid organ transplant recipients. Its benefits have resulted in an important advance in this area of medicine, although some side effects may appear, such as nephrotoxicity, diabetogenicity, tremor, headache, hirsutism, gynecomastia, and gingival enlargement. GE prevalence in these patients varies from $8 \%$ to $81 \% .^{7-9}$ Several different factors have been associated with its appearance, including the presence of plaque, prior inflammation, drug dosage and blood level, length

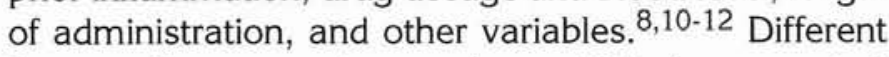
therapeutic approaches, such as strict plaque control and surgery, have been the treatment of choice in the management of GE in these patients. Despite these measures, GE usually recurs after several months. ${ }^{13}$ Because of the importance of maintaining an immunosuppressive level in these individuals, CsA withdrawal was not previously considered as a therapeutic option in the treatment of GE in organ transplant recipients. However, the appearance of new immunosuppressive 
Table I.

\section{Demographic Details and Characteristics of the Four Transplant Patients}

\begin{tabular}{|c|c|c|c|c|c|c|c|c|c|c|c|}
\hline Patient & Gender & - Age & $\begin{array}{c}\text { TST } \\
\text { (months) }\end{array}$ & $\begin{array}{c}\text { Cause of } \\
\text { Transplantation }\end{array}$ & $\begin{array}{l}\text { Type of } \\
\text { Transplant }\end{array}$ & $\begin{array}{l}\text { Dose } \\
\text { of CsA }\end{array}$ & $\begin{array}{l}\text { Serum } \\
\text { Levels } \\
\text { of CsA }\end{array}$ & $\begin{array}{c}\text { Initial } \\
\text { Dose of } \\
\text { Tacrolimus }\end{array}$ & $\begin{array}{l}\text { Serum } \\
\text { Levels of } \\
\text { Tacrolimus }\end{array}$ & $\begin{array}{c}\text { Dose of } \\
\text { Azathioprine }\end{array}$ & $\begin{array}{l}\text { Dose of } \\
\text { Prednisone }\end{array}$ \\
\hline I & M & 58 & 87 & Alcoholic cirthosis & L & $350 \mathrm{mg} / \mathrm{d}$ & $283 \mu \mathrm{g} / \mathrm{ml}$ & $6 \mathrm{mg} / \mathrm{d}$ & $12.6 \mu \mathrm{g} / \mathrm{ml}$ & - & $10 \mathrm{mg} / \mathrm{d}$ \\
\hline 2 & $\mathrm{~F}$ & 49 & 41 & Hepatitis C cirrhosis & L & $300 \mathrm{mg} / \mathrm{d}$ & $235 \mu \mathrm{g} / \mathrm{ml}$ & $10 \mathrm{mg} / \mathrm{d}$ & $14.8 \mu \mathrm{g} / \mathrm{ml}$ & - & $10 \mathrm{mg} / \mathrm{d}$ \\
\hline 3 & $\mathrm{~F}$ & 38 & 29 & Glomerulonephritis & K & $250 \mathrm{mg} / \mathrm{d}$ & $256 \mu \mathrm{g} / \mathrm{ml}$ & $7 \mathrm{mg} / \mathrm{d}$ & $10.2 \mu \mathrm{g} / \mathrm{ml}$ & $50 \mathrm{mg} / \mathrm{d}$ & $5 \mathrm{mg} / \mathrm{d}$ \\
\hline 4 & $M$ & 53 & 72 & Hepatoma & L & $300 \mathrm{mg} / \mathrm{d}$ & $268 \mu \mathrm{g} / \mathrm{ml}$ & $10 \mathrm{mg} / \mathrm{d}$ & $16.2 \mu \mathrm{g} / \mathrm{ml}$ & - & $10 \mathrm{mg} / \mathrm{d}$ \\
\hline
\end{tabular}

$\mathrm{TST}=$ time since transplantation; $\mathrm{L}=$ liver $; \mathrm{K}=$ kidney.

drugs in recent years permits conversion from CsA to other immunosuppressants as a safe and secure therapeutic alternative. Tacrolimus is a xenobiotic immunosuppressant discovered in 1978, which has demonstrated high clinical efficacy to avoid graft rejection in solid organ transplants, through an action mechanism based on the inhibition of the calcineurin pathway. ${ }^{14}$ Tacrolimus and CsA show major differences in their chemical structure, even though they seem to have many actions in common as well as a similar spectrum of side effects. However, a recent study has shown that tacrolimus has no adverse effect on the gingival tissues. ${ }^{15}$ These characteristics have made conversion from CsA to tacrolimus desirable in some cases to reduce GE without any supplementary surgical procedure. ${ }^{16-21}$ Most of these reports deal with single cases or short series, and the effects of an extensive oral hygiene program accompanying the withdrawal of CsA have not been previously analyzed. ${ }^{17}$ The purpose of this preliminary study was to observe the GE course in four transplant recipients receiving CsA followed by conversion to tacrolimus, together with an extensive plaque control program.

\section{MATERIALS AND METHODS}

Four transplant patients who signed an informed consent were included in this pilot study. Demographic characteristics, cause of transplantation, time since transplantation, medication, and dosages are provided in Table 1 . All the patients had received an orthotopic liver or kidney transplantation at the Hospital 12 de Octubre in Madrid at least 1 year previously, and they were under periodic maintenance in the Department of Abdominal Transplant Organs (three liver transplant patients) and the Department of Nephrology (one kidney transplant patient). All the patients were taking different doses of CsA"l (Table 1 ), and they were switched to tacrolimus ${ }^{\#}$ by the transplant team due to the presence of chronic liver graft rejection (patients 1 and 2), hirsutism (patient 3 ), and severe hypertension (patient 4). The patients were eligible for enrollment in this study if they exhibited several criteria, such as the presence of clinically severe GE diagnosed by two dentists with experience in this field (GH, LA); were taking different doses of CsA since transplantation; were not taking any other medication with known gingival side effects; were not suffering from any malignancy or systemic disease with proven secondary effects on the periodontium; and they complied with a periodic oral health care program. Not all the patients were included in this study at the same time, since the circumstances that led the transplant team to change the medication occurred at different times. The four patients included in this study were selected over an 11 -month period.

One week before withdrawal of CsA, the patients were examined according to the clinical protocol used by the Department of Oral Medicine and Buccofacial Surgery. The initial examination included a complete medical history, physical examination, complete blood analysis, including blood levels of CsA (Table 1), and intraoral examination. Gingival overgrowth was assessed by one of the examiners (GH) according to the gingival overgrowth index (SI) proposed by Seymour et al., ${ }^{22}$ with slight variations. The 10 papillae between the canines were measured in the lower teeth because this area is usually the most commonly affected. ${ }^{23,24}$ Since any gingival unit may reach a

I Neoral, Novartis Pharma S.A Laboratories, Basel, Switzerland. \# Prograf, Fujisawa Laboratories, Osaka, Japan. 
maximal score of 5 and 10 gingival units ( 5 labial, 5 lingual) were examined, a maximal score of 5 could be obtained after the sum of the values of the 10 papillae examined were divided by 10 . The measurements were made on the patient. In order to obtain an objective opinion on the clinical results and to assess the clinical significance of the variations of gingival overgrowth and the degree of satisfaction achieved by the non-dentist colleagues and the patients, the index developed by Harris and Ewart $(\mathrm{HEI})^{25}$ was scored by two non-dentist physicians (CJ, AA), three dentists (LA, MCF, JCV), and each of the patients. The gingival appearance was recorded as follows: 0 , normal clinical appearance; 1 , slight variation in the size of the gingiva; 2 , moderate alteration in the size of the gingiva; 3 , severe alteration in the size of the gingiva. A mean score of the six measurements was obtained for each patient at the different time intervals. Clinical color photographs were recorded at baseline and 54 weeks using slide film. * *

After the gingival parameters were recorded, patients were instructed in oral hygiene techniques, and scaling and root planing (SRP) were performed by quadrants under local anesthesia with lidocaine $0.1 \%$ epinephrine on 4 consecutive days, except patient 4 who was treated in 1 day. No antibiotic therapy was administered before or after these procedures were performed, but clorhexidine (CHX) $0.12 \%$ mouthrinses were prescribed during the procedure and maintained for 1 week thereafter.

At baseline, conversion of CsA to tacrolimus was carried out according to the protocol used by the transplant team (Table 1). SRP was performed in one session each month after baseline during the first 6 months, and careful polishing of the teeth once every 2 weeks until month 6 and monthly until month 12. Clinical data were recorded at baseline, at weeks $2,4,8,12$, and 16 , and 1 year (54 weeks) following conversion to tacrolimus. During each appointment, all patients received instructions and reinforcement to optimize oral hygiene.

To analyze whether there were statistically significant differences among means of SI between all periods, a repeated measures analysis of variance (ANOVA) test was applied. ${ }^{\dagger \dagger}$ To test differences among the GE evolution levels measured with the $\mathrm{SI}$, contrasts comparing the means of each time period to the subsequent time period were applied.

\section{RESULTS}

Except for one of the patients (patient 3), who presented signs of liver rejection 8 months after the begin- ning of the study (treated with a short burst of steroids [ $1 \mathrm{~g}$ of methylprednisolone daily for 3 consecutive days] and by increasing the dose of tacrolimus up to $10 \mathrm{mg} / \mathrm{d}$, with satisfactory results), no signs of liver or renal failure were observed after conversion to tacrolimus, and the clinical and laboratory parameters managed by the transplant team were within normal limits during the study. Adverse effects from tacrolimus were reported by one patient (patient 1) who reported headaches.

GE scores at conversion and at 2, 4, 8, 12, 16, and 54 weeks are shown in Table 2. Initial GE scores showed high values when measured either by the SI (mean 4.9) or the HEl (mean 3). Gingival overgrowth was reduced progressively during the study (Fig. 1), although the reduction was more evident after the second month. Initial reduction after 2 weeks was $0 \%$ in three patients and $4 \%$ in patient 3 , but at that time, the four patients reported an improvement of their symptoms in terms of a decrease in gingival pain and more comfort during oral hygiene procedures. One month after CsA withdrawal, GE decreased a mean of $3.5 \%$, but the four patients felt a clear absence of gingival pain and a marked reduction in spontaneous gingival bleeding. Differences between means of SI values between baseline and 2- and 4week recalls were not statistically significant. A large reduction of GE was observed at the 8-week recall, with a mean $22.5 \%$ decrease in GE $(P<0.05)$. Subsequently, statistically significant $(P<0.05)$ dramatic changes were observed in all periods (Table 2), and gingival anatomy was considered clinically and esthetically normal by the non-dentist coworkers and by the patients at week 16 . One year after CsA was withdrawn, the gingival size was considered clinically normal according to the $\mathrm{HEl}$, except by one of the examiners who considered that one patient (patient 3) maintained a slight variation in the size of the gingiva (mean HEl: 0.16) (Fig. 2). In this patient and in patient 2, the gingiva did not achieve a satisfactory morphology according to two of the examiners.

The repeated measures ANOVA results showed that there was a highly statistically significant $(P<0.0005)$ difference between GE means at different time periods. A contrast test identified six homogeneous groups showing progressively decreasing means. There were statistically significant differences between means of all periods with respect to subsequent periods, except

\footnotetext{
** Ektachrome 100 Plus Professional, Kodak Ltd., Hemel Hempstead, U.K.

$\dagger+$ SPSS 10.0, SPSS Inc., Chicago, IL.
} 


\section{Case Series}

Table 2.

\section{Evolution of Gingival Enlargement Measured by SI and Harris-Ewart Index (HEI) in the Four Patients}

\begin{tabular}{|c|c|c|c|c|c|c|c|c|c|c|c|c|c|c|}
\hline \multirow[b]{3}{*}{ Patient } & \multirow[b]{3}{*}{ Index } & \multicolumn{13}{|c|}{ Period (Weeks) } \\
\hline & & \multirow{2}{*}{$\begin{array}{c}\text { Baseline } \\
\text { Index } \\
\text { Value }\end{array}$} & \multicolumn{2}{|c|}{2} & \multicolumn{2}{|c|}{4} & \multicolumn{2}{|c|}{8} & \multicolumn{2}{|c|}{12} & \multicolumn{2}{|c|}{16} & \multicolumn{2}{|c|}{54} \\
\hline & & & $\begin{array}{l}\text { Index } \\
\text { Value }\end{array}$ & \%* & $\begin{array}{l}\text { Index } \\
\text { Value }\end{array}$ & \%* & $\begin{array}{l}\text { Index } \\
\text { Value }\end{array}$ & $\% *$ & $\begin{array}{l}\text { Index } \\
\text { Value }\end{array}$ & $\% *$ & $\begin{array}{l}\text { Index } \\
\text { Value }\end{array}$ & \%* & $\begin{array}{l}\text { Index } \\
\text { Value }\end{array}$ & $\% *$ \\
\hline 1 & $\begin{array}{l}\text { SI } \\
\text { HEI }\end{array}$ & $\begin{array}{l}5.0 \\
3.0\end{array}$ & $\begin{array}{l}5.0 \\
3.0\end{array}$ & 0 & $\begin{array}{l}4.8 \\
2.7\end{array}$ & 4 & $\begin{array}{l}4.5 \\
1.8\end{array}$ & 10 & $\begin{array}{l}1.6 \\
1.0\end{array}$ & 68 & $\begin{array}{l}1.0 \\
0.2\end{array}$ & 80 & $\begin{array}{l}0.2 \\
0.0\end{array}$ & 96 \\
\hline 2 & $\begin{array}{l}\text { SI } \\
\text { HEI }\end{array}$ & $\begin{array}{l}4.8 \\
3.0\end{array}$ & $\begin{array}{l}4.8 \\
3.0\end{array}$ & 0 & $\begin{array}{l}4.7 \\
2.8\end{array}$ & 2 & $\begin{array}{l}3.8 \\
2.2\end{array}$ & 21 & $\begin{array}{l}1.4 \\
0.7\end{array}$ & 71 & $\begin{array}{l}1.2 \\
0.2\end{array}$ & 75 & $\begin{array}{l}0.3 \\
0.0\end{array}$ & 93 \\
\hline 3 & $\begin{array}{l}\text { SI } \\
\text { HEI }\end{array}$ & $\begin{array}{l}4.8 \\
3.0\end{array}$ & $\begin{array}{l}4.6 \\
3.0\end{array}$ & 4 & $\begin{array}{l}4.4 \\
3.0\end{array}$ & 8 & $\begin{array}{l}2.9 \\
1.8\end{array}$ & 39 & $\begin{array}{l}0.7 \\
1.3\end{array}$ & 82 & $\begin{array}{l}0.3 \\
0.3\end{array}$ & 93 & $\begin{array}{l}0.2 \\
0.2\end{array}$ & 95 \\
\hline 4 & $\begin{array}{l}\text { SI } \\
\text { HEI }\end{array}$ & $\begin{array}{l}5.0 \\
3.0\end{array}$ & $\begin{array}{l}5.0 \\
3.0\end{array}$ & 0 & $\begin{array}{l}5.0 \\
3.0\end{array}$ & 0 & $\begin{array}{l}4.0 \\
2.2\end{array}$ & 20 & $\begin{array}{l}1.8 \\
1.0\end{array}$ & 64 & $\begin{array}{l}0.8 \\
0.2\end{array}$ & 84 & $\begin{array}{l}0.1 \\
0.0\end{array}$ & 98 \\
\hline Mean (SI only) & & 4.90 & 4.85 & 1 & 4.73 & 3.5 & 3.80 & 22.5 & 1.38 & 71.25 & 0.83 & 83 & 0.20 & 95.5 \\
\hline
\end{tabular}

* Percentage decrease with respect to baseline SI.

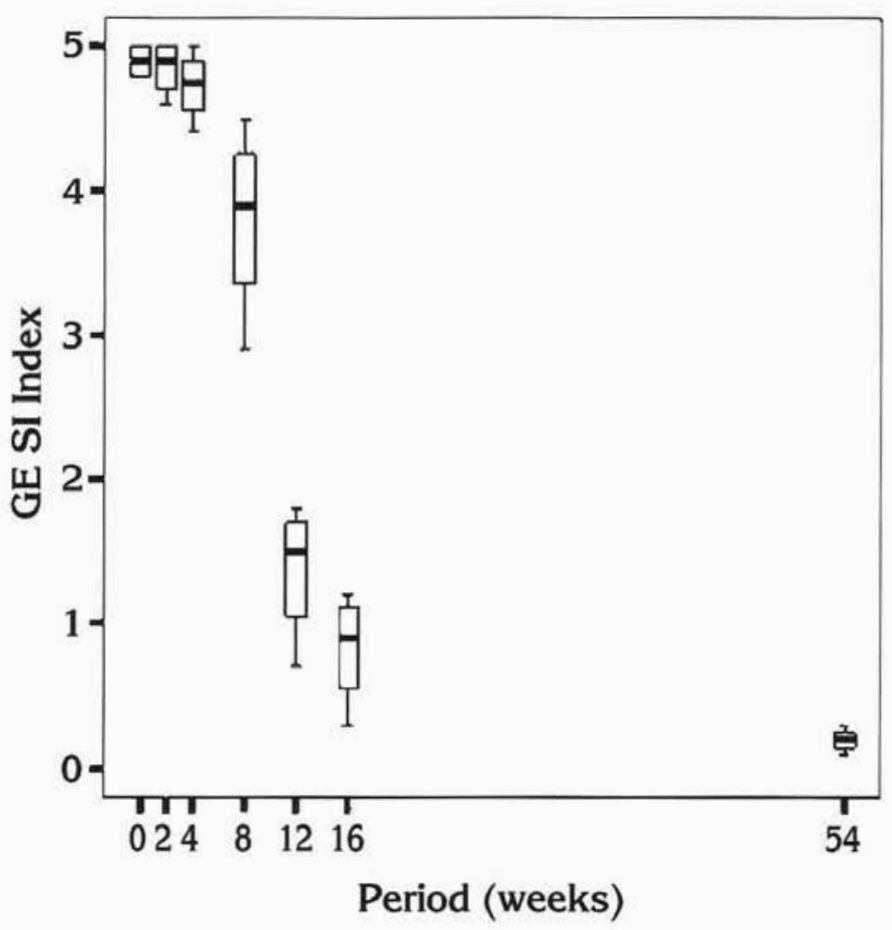

Figure $I$.

Box plot of measurements of gingival overgrowth evolution throughout the study. between baseline and week 2 means and between week 2 and 4 means.

Length of time on CsA seemed to have no relationship to the completeness of resolution of gingival enlargement. All four patients showed a similar pattern in the progression of the reduction of gingival enlargement.

\section{DISCUSSION}

Although the sample size of this preliminary study was small, the results may suggest that withdrawal of CsA and conversion to tacrolimus, together with an extensive plaque control program, may be an effective and safe alternative to reduce gingival enlargement severity in a short period of time.

Mean initial (baseline) gingival overgrowth in this group of patients as measured by the SI was 4.9 and this may be considered as clinically severe, according to other similar studies, where scores of 2 to 3 or more were considered clinically significant, $24,26,27$ and represents overgrowth that warrants surgical excision. ${ }^{26}$ Regression of GE to a normal level in the four cases reported in this study has not always been described previously in other similar studies. One possible explanation is that the patients we studied were not taking any other medication with proven effects on the gingiva except $\mathrm{CsA}$, and although the 


\section{Case Series}
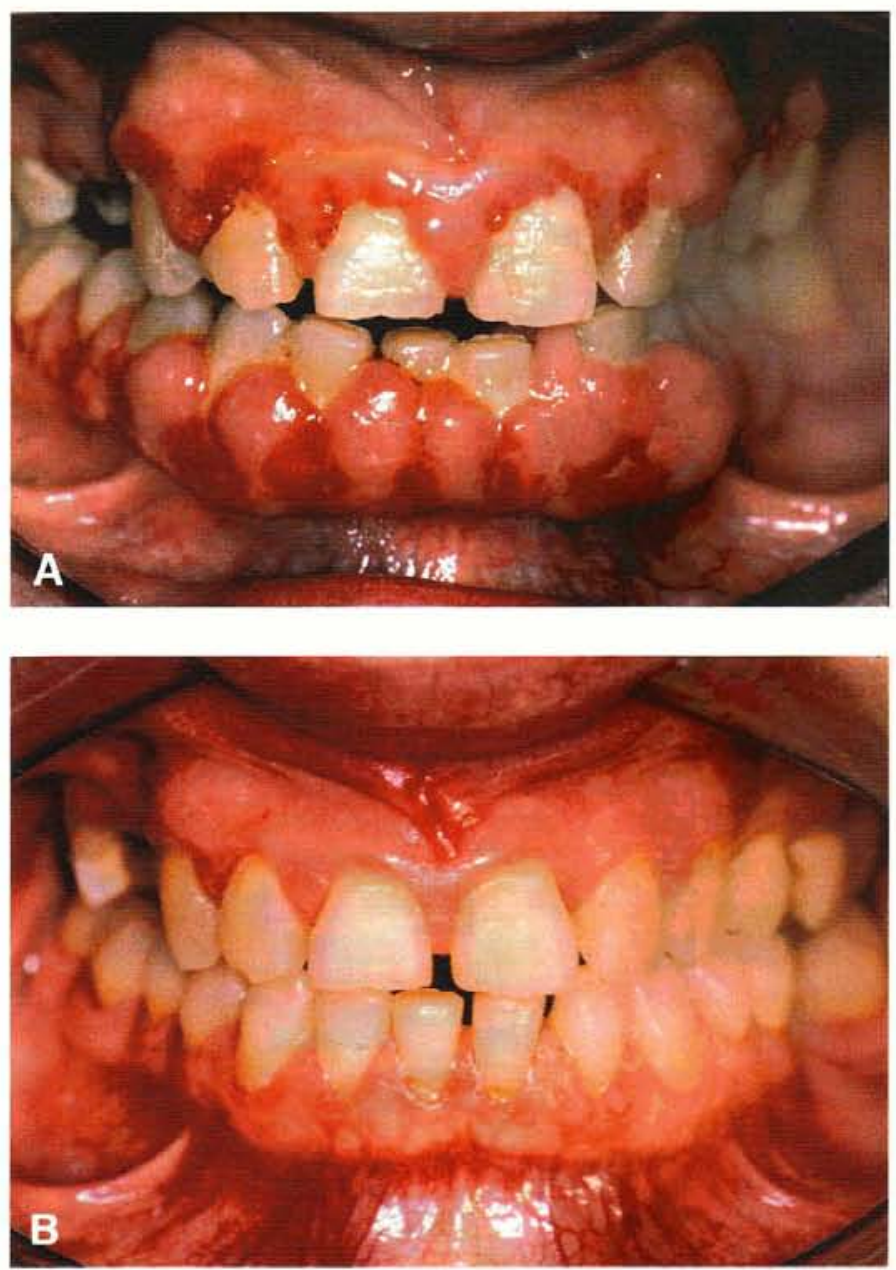

Figure 2.

A) Initial gingival enlargement in patient 3. B) Clinical picture of the gingiva upon completion of treatment Note that in some interdental spaces, several irregularities of the papillae persist.

initial GE was much more severe than in other similar studies, ${ }^{17,28}$ the GE was related exclusively to the administration of this drug. Other studies have demonstrated that conversion from CsA to tacrolimus produced a significant clinical reduction of GE even in cases where other drugs such as nifedipine ${ }^{17}$ and phenytoin ${ }^{16}$ were administered together. In these cases, the reduction of GE was not so dramatic as in the cases reported in this article, which might be due to the fact that those drugs were not withdrawn. In the cases described by James et al., ${ }^{17}$ three out of four patients did not show complete regression after 9 months, but those patients were receiving CsA and calcium channel blocking agents to control their hypertension, and this association may have a synergistic effect on the gingiva. ${ }^{10,29}$ Recently, we have reported a case of very severe $G E$ in a patient taking CsA and phenytoin; ${ }^{16}$ although a significant improvement was observed after 6 months of CsA withdrawal, total reduction was not achieved due to continued administration of phenytoin, which could not be withdrawn.

The presence of gingival inflammation could be another factor that might be responsible for the incomplete reduction of GE once CsA has been withdrawn. ${ }^{13}$ In our study, an intensive oral health program accompanied the withdrawal of CsA. The role of gingival inflammation in the GE regression rate seems to be important. In the cases reported by Thorp et al., ${ }^{18}$ from six patients exhibiting GE, two patients reverted to a normal gingival status in 4 months, one in 8 months, one in 12 months (complete resolution: $67 \%$ ), and two patients did not achieve complete regression after 1 year, although the improvement was significant. These two patients displayed a more severe GE, and neither was taking any other medication with known effects on the gingiva. However, initial scores of the gingival hyperplasia index were much lower than in our patients. No data regarding the hygiene measures carried out during their study, if any, were described. This may mean that the presence of plaque and inflammation might delay the regression of GE in these patients once CsA is switched to tacrolimus. In our cases, professional hygienic procedures were extensively carried out. Although during the first weeks after CsA withdrawal the patients could not effectively remove the plaque due to the severity of $\mathrm{GE}$, professional measures such as scaling and root planing and polishing were performed thoroughly during the study, so the patients showed minimal gingival inflammation.

The exact role played by plaque control and withdrawal of CsA on the improvement of GE remains unclear. It has been shown in cases of GE that patients undergoing professional cleaning experienced a statistically significant decrease of $12.1 \%$ in the gingival overgrowth, and those who also underwent scaling and curettage had a decrease of $18.2 \%$ between months 6 and 12 after transplantation. ${ }^{30}$ Kantarci et al. ${ }^{31}$ reported that after oral hygiene instructions, supra- and subgingival scaling, polishing, and gingival curettage, the initial gingival overgrowth scores were reduced from $53.40 \%$ to $32.13 \%$ after 8 weeks, a reduction of $21.27 \%$. Although we did not perform closed curettage in our patients, which offers no benefit when combined with scaling and root planing, the initial effect of scaling and root planing on GE reduction seems to be important, at least in terms of reduction of the inflammation. 
The patients initially observed a more comfortable gingival sensation and disappearance of the pain in 10 days. Moreover, after 8 weeks, the reduction of GE in our patients was $10 \%, 21 \%, 39 \%$, and $20 \%$, respectively. This represented greater improvement than that achieved when tooth cleaning, ${ }^{30}$ scaling and root planing, ${ }^{30}$ closed curettage, ${ }^{31}$ or even gingivectomy ${ }^{32}$ are used, and these findings may suggest that the differences are due to the cessation of the effect of CsA. However, there are contradictory results in this respect and, paradoxically, other studies have shown that patients receiving hygienic procedures present fewer benefits in their GE once CsA is withdrawn. ${ }^{17}$ This is an interesting and curious observation, and in light of our experience, we cannot offer a satisfactory explanation. One possible cause is that those GE that are more fibrous respond less favorably to hygiene measures than those that display a more severe inflammatory/edematous component. Patient 3 in our study initially displayed a very inflammatory/edematous gingival appearance and was the patient who responded more quickly to the change of medication. In this regard, it would be very interesting to know how much influence the presence of plaque and gingival inflammation has in the regression of $\mathrm{GE}$, in terms of quantity and length, and the exact role that the withdrawal of the drug plays. The small number of cases in this report does not permit assessment of these factors and should be analyzed in a separate study designed to answer these questions.

Length of time in which GE reduction is achieved showed some variation, but it seems that 4 months are necessary to achieve satisfactory results, at least in terms of esthetics. In our study, the four patients showed satisfaction with the appearance of their gingiva after 4 months. Patients reported by James et al. ${ }^{17}$ were satisfied with the esthetic appearance of their gingiva after 6 months, although the final GE scores were higher than in our study and the percentage of reduction was lower, except for patient 3 in the James et al. study who showed an $82.3 \%$ improvement. Regression of gingival hyperplasia was also rapid in the cases described by Thorp et al., ${ }^{18}$ and several patients displayed complete regression by 4 months, although in others, the reduction continued up to 1 year and was not complete. It has been stated that the lack of complete response after 6 to 9 months may be due to physiological inability for tissue remodeling, since breakdown of large numbers of extracellular matrix macromolecules is necessary in these cases. ${ }^{17}$ The results of our preliminary study do not support that observation, and 4 months seem adequate to achieve the disappearance of the hypertrophic tissue. It may be that differences in the amount of the inflammatory component might help to explain these discrepancies. Although our patients showed a more severe GE than in other similar studies, perhaps the inflammatory component was also higher, and this was responsible for the reduction of $\mathrm{GE}$. This is achieved sooner in edematous responses than in cases of a more fibrotic nature. These two gingival patterns, either fibrotic, with a firm fibrous nodular aspect, or edematous, accompanied by pink coloration, erythema, swollen aspect, gingival mobility on probing, and spontaneous bleeding, have been previously reported. ${ }^{19}$ In addition, an important consideration regarding the different healing responses might be ethnic differences in the populations that are being studied.

Other questions that require additional study include the role of some variables which may influence the amount and progression of the GE reduction, once $\mathrm{Cs} A$ is changed to tacrolimus, for example, the preexisting level of GE and the length of time of GE. Considering the small number of cases in our study, we cannot respond to the first question, since all of the patients initially showed the same degree of GE and the regression of GE showed a uniform pattern. With respect to the role of the duration of GE, we could not state this variable exactly; however, the reduction was achieved in the same way in all four patients, although the time the patients had been taking CsA was different.

One of the initial obstacles faced in this study was finding enough patients who met the study criteria. Transplantation teams are seldom predisposed to change the immunosuppressive regimen unless some systemic side effects due to CsA appear. Despite some studies in which withdrawal of CsA has been carried out due only to the presence of GE, 16,17,26 it is difficult to get a change in the immunosuppressant if GE appears as the only complication. Tacrolimus is a xenobiotic immunosuppressant isolated from microbial broths (Streptomyces tsubakensis) $^{33}$ that acts through the inhibition of interleukin (IL)-2 and other growth-promoting cytokine dependent T-cell activation. ${ }^{14}$ Different studies conducted in the United States and Europe have demonstrated that tacrolimus shows similar patient and graft survival in both liver and kidney transplantation as CsA, and that there is a consistent statistically significant advantage for tacrolimus with respect to acute rejection rate. ${ }^{34}$ Since tacrolimus has been demonstrated to be a safe and secure alternative to CsA, its use has become widespread in solid organ transplan- 
tation in cases of primary immunosuppression, ${ }^{34,35}$ and conversion therapy to tacrolimus successfully provides an alternate treatment as rescue therapy in cases of rejection. ${ }^{36}$

\section{ACKNOWLEDGMENT}

The authors would like to thank Dr. Steve Gold, Columbia University, New York, New York, for reviewing this manuscript.

\section{REFERENCES}

1. Angelopoulous AG. Diphenylhydantoin gingival hyperplasia. A clinicopathological review. 1. Incidence, clinical features and histopathology. J Can Dent Assoc 1975;41:103-106.

2. Jones CM. Gingival hyperplasia associated with nifedipine (letter to the editor). Br Dent J 1986;160:416-417.

3. Rateitschak-Pluss EM, Hefti A, Lortscher R, Thiel G. Initial observations that cyclosporin-A induces gingival enlargement in man. J Clin Periodontol 1983;10:273-276.

4. Arora PD, Silvestri L, Ganss B, Sodek J, McCulloch CA. Mechanism of cyclosporin-induced inhibition of intracellular collagen degradation. J Biol Chem 2001;276: 14100-14109.

5. Rocha LA, Martins RC, Werneck CC, Feres-Filho EJ, Silva LC. Human gingival glycosaminoglycans in cyclosporin-induced overgrowth. J Periodont Res 2000; 35:158-164.

6. Calne RY, White DJG, Thiru S. Cyclosporin A in patients receiving renal allografts from cadaver donors. Lancet 1978;2:1323-1327.

7. Pernu HE, Pernu LMH, Huttunen KRH, et al. Gingival overgrowth among renal transplant recipients related to immunosuppressive medication and possible local background factors. J Periodontol 1992;63:548-553.

8. Somacarrera ML, Hernández G, Acero J, Moskow BS. Factors related to the incidence and severity of cyclosporin-induced gingival overgrowth in transplant patients. A longitudinal study. J Periodontol 1994;65: 671-675.

9. Thomason JM, Seymour RA, Rice N. The prevalence and severity of cyclosporin-and nifedipine-induced gingival hyperplasia. J Clin Periodontol 1993;20:37-40.

10. Spratt H, Boomer S, Irwin CR, et al. Cyclosporinassociated gingival overgrowth in renal transplant recipients. Oral Dis 1999;5:27-31.

11. Thomas DW, Newcombe RG, Osborne GR. Risk factors in the development of cyclosporine-induced gingival overgrowth. Transplantation 2000;69:522-526.

12. Seymour RA, Ellis JS, Thomason JM. Risk factors for drug-induced gingival overgrowth. J Clin Periodontol 2000;27:217-223.

13. Ilgenly T, Atilla G, Baylas H. Effectiveness of periodontal therapy in patients with drug-induced gingival overgrowth. Long-term results. J Periodontol 1999;70: 967-972.

14. Peters DH, Fitton A, Plosker GL, Faulds D. Tacrolimus: A review of its pharmacology, and therapeutic potential in hepatic and renal transplantation. Drugs 1993;
46:746-794

15. James JA, Jamal S, Hull PS, et al. Tacrolimus is not associated with gingival overgrowth in renal transplant patients. J Clin Periodontol 2001;28:848-852.

16. Hernández G, Arriba L, Lucas $M$, de Andrés A. Reduction of severe gingival overgrowth in a kidney transplant patient by replacing cyclosporin A with tacrolimus. J Periodontol 2000;71:1630-1636.

17. James JA, Boomer S, Maxwell AP, et al. Reduction in gingival overgrowth associated with conversion from cyclosporin A to tacrolimus. J Clin Periodontol 2000;27: 144-148.

18. Thorp M, DeMattos A, Bennet W, Barry J, Norman D. The effect of conversion from cyclosporine to tacrolimus on gingival hyperplasia, hirsutism and cholesterol. Transplantation 2000;69:1218-1224.

19. Bader G, Lejeune S, Messner M. Reduction of cyclosporine-induced gingival overgrowth following a change to tacrolimus. A case history involving a liver transplant patient. J Periodontol 1998;69: 729-732.

20. Kennedy DS, Linden GJ. Resolution of gingival overgrowth following change from cyclosporin to tacrolimus therapy in a renal transplant patient. J Ir Dent Assoc 2000;46:3-4.

21. Busque S, Demers P, St Louis G, et al. Conversion from Neoral (cyclosporine) to tacrolimus of kidney transplant recipients for gingival hyperplasia or hypertrychosis. Transplant Proc 1998;30:1247-1248.

22. Seymour RA, Smith DG, Turnbull DN. The effects of phenytoin and sodium valproate on the periodontal health of adult epileptic patients. J Clin Periodontol 1985; 12:413-419.

23. Somacarrera ML, Hernández G, Acero J, Moskow BS. Localization of gingival overgrowth in heart transplant patients undergoing cyclosporin therapy. J Periodontol 1994;65:666-670.

24. Thomason JM, Kelly PJ, Seymour RA. The distribution of gingival overgrowth in organ transplant patients. $J$ Clin Periodontol 1996;23:367-371.

25. Harris TH, Ewart JR. Complications following the use of sodium diphenylhydantoinate (Dilantin) therapy. J Okl Med Assoc 1942;35:365-370.

26. Ellis JS, Seymour RA, Robertson P, Butler TJ, Thomason JM. Photographic scoring of gingival overgrowth. J Clin Periodontol 2001;28:81-85.

27. Thomason JM, Seymour RA, Rawlins MD. Incidence and severity of phenytoin-induced gingival overgrowth in epileptic patients in general medical practice. Community Dent Oral Epidemiol 1992;20:288-291.

28. Kohnle M, Lütkes P, Zimmermann U, Philipp T, Heemann U. Conversion from cyclosporine to tacrolimus in renal transplant recipients with gum hyperplasia. Transplant Proc 1999;31(Suppl. 7a):44-45.

29. Santi E, Bral M. Effect of treatment on cyclosporineand nifedipine-induced gingival enlargement: Clinical and histologic results. Int J Periodontics Restorative Dent 1998;18:80-85.

30. Somacarrera ML, Lucas M, Scully C, Barrios C. Effectiveness of periodontal treatments on cyclosporineinduced gingival overgrowth in transplant patients. $\mathrm{Br}$ Dent 1997;183:89-94. 


\section{Case Series}

31. Kantarci A, Cebeci I, Tuncer Ö, Çarin M, Firatli E. Clinical effects of periodontal therapy on the severity of cyclosporin A-induced gingival hyperplasia. J Periodontol 1999;70:587-593.

32. Pilloni A, Camargo PM, Carere M, Carranza FA Jr. Surgical treatment of cyclosporine A- and nifedipineinduced gingival enlargement: Gingivectomy versus periodontal flap. J Periodontol 1998;69:791-797.

33. Kino T, Hatanaka H, Hashimoto $\mathrm{H}$, et al. FK-506, a novel immunosuppressant isolated from a Streptomyces. I. Fermentation, isolation, and physico-chemical and biological characteristics. J Antibiot (Tokyo) 1987;40:12491255.

34. Plosker GL, Foster RH. Tacrolimus: A further update of its pharmacology and therapeutic use in the management of organ transplantation. Drugs 2000;59: 323-389.

35. Rolles K, Davidson BR, Burroughs AK. A pilot study of immunosuppressive monotherapy in liver transplantation: Tacrolimus versus microemulsified cyclosporin. Transplantation 1999;68:1195-1209.

36. Sarahrudi K, Carreta A, Wisser W, et al. The value of switching from cyclosporine to tacrolimus in the treatment of refractory acute rejection and obliterative bronchiolitis after lung transplantation. Transplant Int 2002; 15:24-28.
Correspondence: Prof. G. Hernández Vallejo, Departamento de Medicina y Cirugía Bucofacial, Facultad de Odontología, Ciudad Universitaria s/n, 28040 Madrid, Spain. Fax: 34913941910; e-mail: ghervall@odon.ucm.es.

Accepted for publication April 30, 2003. 